\title{
Investigating English Academic Writing Problems Encountered by Arab International University Students
}

\author{
Sarah Al-Mukdad \\ Arab International University (AIU), Damascus, Syria
}

\begin{abstract}
This study is in the area of Teaching English as a Foreign Language (TEFL). It aimed to investigate the academic writing problems encountered by students at Arab International University (AIU) who are taking the Academic Writing module (AWR). The purpose of the study is to investigate this problem from the perspective of students in order to suggest possible treatments to deal with it. The data was collected through distributing a questionnaire to 50 students from different majors at AIU. Upon analyzing and discussing the obtained data, results suggest that students tend to perceive all aspects of academic writing to be difficult. One reason is that they poorly recognize the difference between academic and general English writing due to the lack of background knowledge about writing academically. Another prime reason is attributed to having problems in different linguistic elements even at this supposedly high proficiency level. The study concludes with suggesting a number of ways to address this issue.
\end{abstract}

Index Terms - writing skill, academic writing, writing challenges, foreign language, students' perspectives

\section{INTRODUCTION}

Knowing any language requires mastering its different skills, and writing is one of the most important amongst other skills because it is the clear evidence of being in control of the foreign language. Yet, it is one of the most perplexing skills to many students; they suffer greatly in developing their writing skills which can result in causing many problems in their writing attempts and can develop a negative impact on their overall written output.

Writing is one of the most challenging skills that second or foreign language learners are expected to acquire as it requires the mastery of a variety of "linguistic, cognitive, and sociocultural competencies" (Barkaoui, 2007). To go more in depth, academic writing has an essential role in "socializing students into the discourse of subjects and disciplines in universities" (Pineteh, 2014). Writing academically has always been very important in the field of teaching English to speakers of other Languages.

One reason is attributed to the need of this skill in higher education (Al Badi, 2015). That is why it is crucial to study and conduct research on the difficulties students face in their attempts to produce academic writing in order to suggest remedies for this serious problem.

Research questions:

The study attempts to provide answers to the following questions:

1. What are the academic writing problems amongst AIU students taking AWR course?

2. What are some possible ways to address these problems?

Significance of the study:

It has been a common criticism often heard in Syria that a lot of university students are unable to express themselves in a comprehensible manner in writing. Therefore, this study has a dual purpose; first, to shed light on the challenges faced by AIU students when writing academically, and second to provide certain remedies for such a problem. This study is a crucial issue to be dealt with as it tackles an essential realization and projection of academic writing skills.

Literature review:

Abdulkareem characterizes academic writing as being "The construction and development of techniques taught in universities such as organizing and generating students' ideas and critical thinking, and developing vocabulary and grammatical syntax" (2013, p.1553).

Writing is "a complex process" as Al Badi (2015, p. 65) describes it and according to Al Fadda, "Academic writing in English at advanced levels is a challenge even for most native English speakers" (2012, p. 123). Academic Writing has a very important role to play in acquiring a foreign language. It includes a number of essential elements such as critical thinking and self- expression. Also, techniques that involve paraphrasing and summarizing cannot be overlooked in academic writing (Abdulkareem, 2013). This is a fact especially working on research papers as students have to use other people's works by exploiting those references into their own voice.

Writing is studied from two basic theoretical viewpoints: cognitive and socio-cultural. "The cognitive perspective is goal-oriented and emphasizes the process of writing and revising whereas the socio-cultural perspective is contextoriented and emphasizes the product of writing for a particular audience" (Lee, 2005, p.3). 
Arab students encounter problems in writing because they learn it through the formal instructions inside classroom since they have very limited possibility of using it with native speakers in natural ways (Alfaki, 2015; Al-Khasawneh, 2010; and Rabab'ah, 2003).

\section{Writing problems:}

Not being capable of writing may be a result of the complex nature of the writing skill (Alfaki, 2015). Arab students encounter many problems using the English language to communicate orally or in written forms (Al-Khasawneh, 2010; Rabab'ah, 2003). "Instructors continuously complain about the lack of knowledge and certain skills necessary for academic writing among non-native speakers of English (Al Fadda, 2012, p.125).

So, it is crucial for teachers, according to Lee (2005), to examine the difficulties their students may suffer from so that they develop themselves and help students overcome their problems. Kobayashi \& Rinnert believe that students' writing skills development can be influenced by a number of factors (2008). One reason for this inefficiency goes to students' lack of motivation (Alfaki, 2015; Rabab'ah, 2003). Motivating students is described by Barkaoui in 2007 as a "tricky task." He said: "Motivational factors include learners' beliefs about the nature and importance of writing, the differences between L1 and L2, their attitude to the L2, and about their writing competence, which in turn influence learners' engagement, effort, and learning in the L2 writing classroom" (p.42).

Al-Khasawneh in his study (2010) sates a number of problems that hinder the development of students' writing skills. He finds that "a reasonable vocabulary size is needed for students to function effectively in their programs." And this goes in concordance with Abdulkareem's findings in 2013 that students from Syria regarded using vocabulary and sentence structure as infamous obstacles facing them in academic writing. Another difficulty is related to grammar as Al-Khasawneh describes it to be "extremely important in conveying accurate messages." This is similar to the conclusion of Alfaki in 2015 who regards grammar and sentence structure to be serious problems in addition to word choice.

So, poor language proficiency is a serious point to consider (Al Fadda, 2012). Consequently, it can be deduced that problems in writing academically are due to linguistic deficiency, in addition to students' attitude towards academic writing since they simply approach it with "negativities and misconceptions" (Pineteh, 2014). So, morphology, lexicon, and syntax all need to be learned in order to produce good writing. In this sense, full proficiency results from mastering these competencies (Barkaoui, 2007).

Difficulties go beyond the linguistic elements of the language to reach some problems related to the library research; nonetheless, they do not go in isolation from the cognitive part. For example, paraphrasing can be a source causing difficulties in writing because students read and then write in their own way depending on their understanding. Thus, grammar mistakes can be an expected result (Al Badi, 2015).

In her study, Al Badi (2015) investigates the possible factors that might result in poor academic writing by students who do library research projects. She deduces that paraphrasing, referencing, and citations were reported to be the least problematic which is contrary to Abdulkareem (2013) who assures that students have problems in paraphrasing as their language is not proficient enough for such a technique. However, half of students who participated in her study states that they have to make a concerted effort to choose a topic and support it with appropriate literature. Also, about $88 \%$ of them stated that they tend to make an outline before they begin writing their assignments, but they still have problem while preparing it. Moreover, about $44 \%$ of the participants consider citations and referencing as dilemmata. AlKhasawneh thinks (2010) that students suffer while organizing ideas. Similarly, Al Murshidi in 2014 believed that generating ideas could be a barrier that hinders students to move on in their writing. As a result, low proficiency can be a real cause. So, students would find difficulty expressing their ideas.

\section{Solutions to the writing problems:}

Many students have developed a skill of camouflaging their weakness in writing until they are forced to show their skills and thus where the deficiencies occur. Teachers' role is essential as Isaacson states, "Giving careful feedback will reinforce newly learned skills and correct recurring problems" (1996). Similarly, Al Badi (2015) believes that students need teachers' assistance. Teachers can train students, for instance, to avoid plagiarism while working on their library research. She also stresses the importance of considering students' needs through identifying their problems in a kind of a test. Students should have sufficient opportunities to practice writing continuously. In other words, they can overcome difficulties by practicing. Students should know the processes of writing (generating ideas, planning, drafting, and revising) and teachers have to monitor them with feedback so that students can master those techniques and have learning autonomy (Barkaoui, 2007).

The current study contributes to the research in terms of offering valuable insights into the most difficult aspects of academic writing faced by students at AIU. It highlights the key difficulties from students' point of view. Additionally, it concludes with suggesting some solutions to this problem.

\section{METHODOLOGY}

\section{Course description:}

The present study was conducted during the second term of 2017 academic year. Students who take AWR course should have finished a number of levels which starts from 0 (elementary) to 3 (Upper-intermediate). Classes had an average of 25 students who study different majors at AIU. The course had two parts: in the first one the students had to 
learn how to write different types of essays in an academic way including: opinion essay, comparison/contrast essay, and cause/effect essay.

In the second part, students were required to submit a library research by the end of the semester. They had to decide a research topic, design the research, and write up a research paper. This had the aim of facilitating students' scientific thinking through writing academic papers. The research has 15 marks out of 100 distributed as follows: 5 for submitting a draft in which teachers provide students with a written feedback on the research, 5 for interviewing students on what they did in the research, and 5 for the final submission. The textbook being taught is compiled and edited for AIU.

The instrument:

Data from real life situations of using the English language for academic writing purposes was collected, described, and analyzed. To collect empirical data, a questionnaire, mostly adapted from Elbow \& Belanoff (2000) and Al Badi (2015), was given to learners after the completion of the course to assure they have acquired the needed knowledge and experience to choose their level of agreements on the items provided. The items were modified to fit into the purposes of the current study. As the course was taught in English, the method used for collecting data was applied in English and the content of the questionnaire items all aim at answering the research questions.

Among the 29 items, 17 were adapted from Elbow \& Belanoff (2000). The 29 items included in the questionnaire followed the closed form instead of the open-ended one as the former proves to be easily analyzed (Edwards \& William, 1998). In addition, the presented choices in the questionnaire were: Agree (A) - Neutral (N) - Disagree (D). These variables were included with an attempt to regard different levels of approving or disapproving and to make items easy to interpret.

The first 3 statements in the questionnaire are about students' attitude towards writing. Then the statements from 4 $\rightarrow 7$ focus on the stage of generating ideas for writing purposes. Item 8 is for revising while item 9 sheds light on the editing stage. The linguistic elements role in causing writing problems are discussed in 5 items from $10 \rightarrow 14$. Statements number 15 and 16 seek answers on participants' awareness of the writing process. Statement 17 highlights the issue of motivation. Statements $18 \rightarrow 29$ focus on all the stages of writing research (see appendix 1).

\section{Participants:}

Students of Arab International University (AIU) who take the AWR course can be freshmen or seniors as the course is taken depending on finishing levels (see course description) rather than having it in one specific year. Therefore, their age ranged from 18 to 24 years old. Participants were randomly selected from 5 classes taught by 3 different teachers. Moreover, most of these students were expected to have relatively high English ability as a result of passing a number of levels before. However, students were proved to have limited knowledge and skills of academic writing before starting this course.

TABLE I.

PARTICIPANTS' BIODATA

\begin{tabular}{|l|l|}
\hline Age & Range: $18 \rightarrow 24$; average age: 21 \\
\hline Year of study & First year: $5-$ Second year: $10-$ Third year: $11-$ Fourth year: $15-$ Fifth year: 9 \\
\hline Major & Architecture: 11 - IT: 3 - Civil: $4-$ Art: 6 - Pharmacy: $24-$ BA: 2 \\
\hline
\end{tabular}

\section{Procedure and data analysis:}

The questionnaire was distributed to students in week 13 to assure they have had the required knowledge to answer the questionnaire. Thus reliable data can be collected from them. Furthermore, all of the participants completed the questionnaire in class under their teacher's supervision. The data obtained from the questionnaire was analyzed to calculate students' responses to each item. Finally, the information was analyzed, the findings were discussed and supported by literature, and some recommendations were suggested.

The results are directly presented after each related question; furthermore, findings are classified in appropriate charts and figures to be clarified and explained afterwards.

\section{RESULTS AND ANALYSIS}

This section presents answers to the two questions raised in this study. The answers are based on analyzing data collected from the questionnaire which was distributed to students toward the end of the AWR course.

\section{What are the writing problems amongst AIU students taking the AWR course?}

First, 3 items in the questionnaire seek to discover students' attitude towards the writing skill. 22\% denied any kind of enjoyment in writing while $30 \%$ preferred to choose the neutral option. However, $48 \%$ assured enjoying writing. $44 \%$ of students proved that they would not write for pleasure in their free time. $28 \%$ believed they have poor academic writing skills while $34 \%$ chose to be neutral regarding this item. Choosing to be neutral can highlight participants' lack of awareness and knowledge of assessing themselves as being good or bad. Moreover, when participants prefer to be neutral in their selection it can be explained as they are timid to express their opinion. So, it can be deduced that AIU students generally have a rarely positive attitude toward writing.

With regard to the stage of generating ideas for writing purposes, $46 \%$ of students confirmed their ability to brainstorm ideas (item 4) especially if the topic was of interest to them as the result of item 6 shows (50\%). This contradicts the study of Jimenez, Esmeralda, Mira, Cecelia, and Stephany (2013) who concluded that students 
considered brainstorming as the most perplexing writing technique. Also, Asadifard and Koosha (2013) research showed that $92 \%$ of participants are reluctant to write because they cannot organize their thoughts. Concerning the revising stage, more than half of the participants thought they have difficulty revise their writing as they have no ability to see their own mistakes (see figure 1).

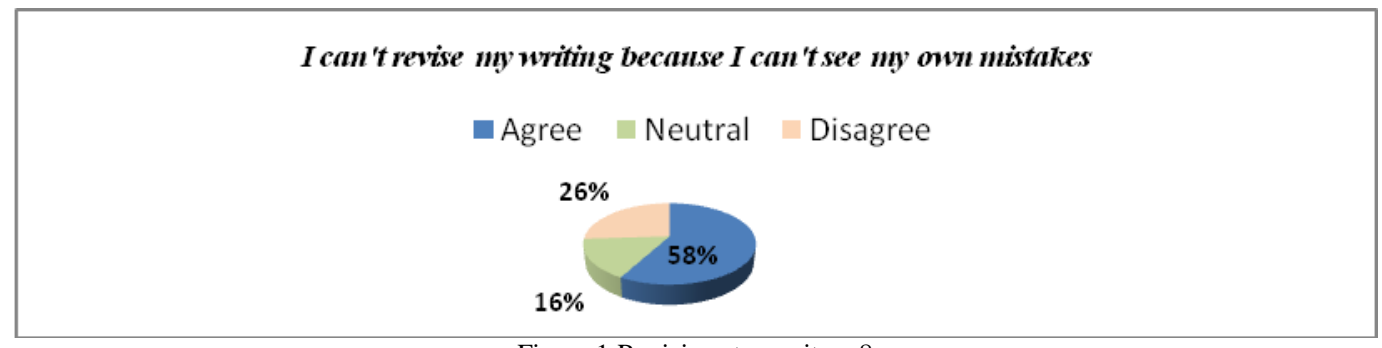

Figure 1.Revising stage - item 8

Linguistic competence is usually perceived by EFL students as the most infamous reason causing writing difficulties (Mojica, 2010). The students in the research of Asadifard and Koosha (2013) stated that one major difficulty they face is the insufficient linguistic skills. Likewise, this study showed that the grammatical features of the language can cause students difficulties in writing (see figure 2).

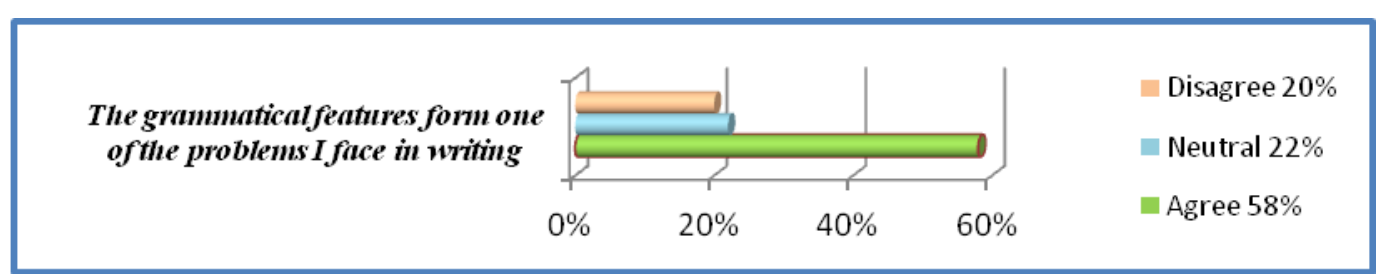

Figure 2.The grammatical features role - item 12

However, AIU students suffer less regarding using appropriate vocabulary since $48 \%$ thought they can use the required expressions and words to express their ideas and this opposes Abdulkareem's study in 2013 who deuced that Syrian students view vocabulary to be a source of trouble they face in academic writing. Nevertheless, students pay more attention to the linguistic elements in general (spelling, grammar, and vocabulary) than to the content and the organization of their ideas (see figure 3). To enhance this point, participants in item 28 claimed that what they suffer from the most in writing academically is the language use (54\%).

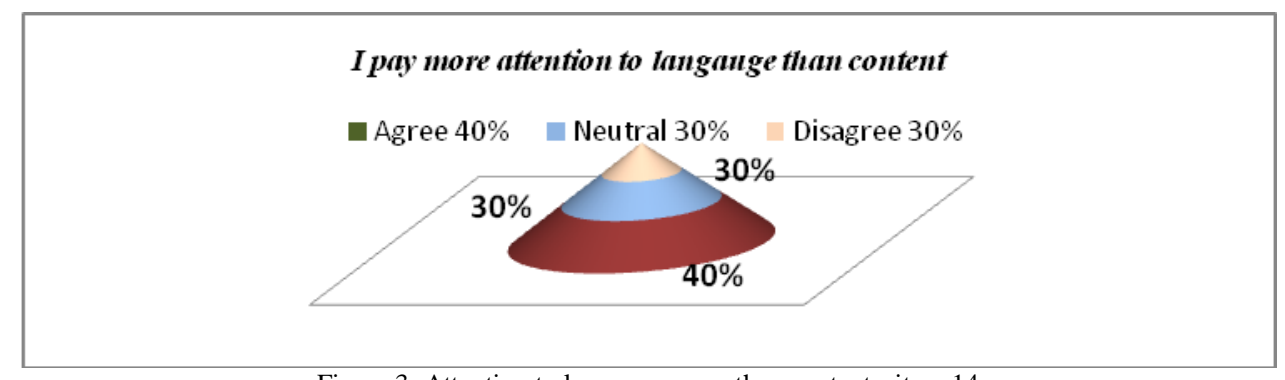

Figure 3. Attention to language more than content - item 14

Not all participants demonstrated ability to identify the problems they have in their writing. $40 \%$ asserted their capability of detecting the mistakes whereas 34\% do not have this skill. Motivation plays an essential part as $60 \%$ of participants agreed on the need of inspiration to write perfectly which is similar to the findings of Alfaki's (2015) and Rabab'ah in 2003 (see figure 4).

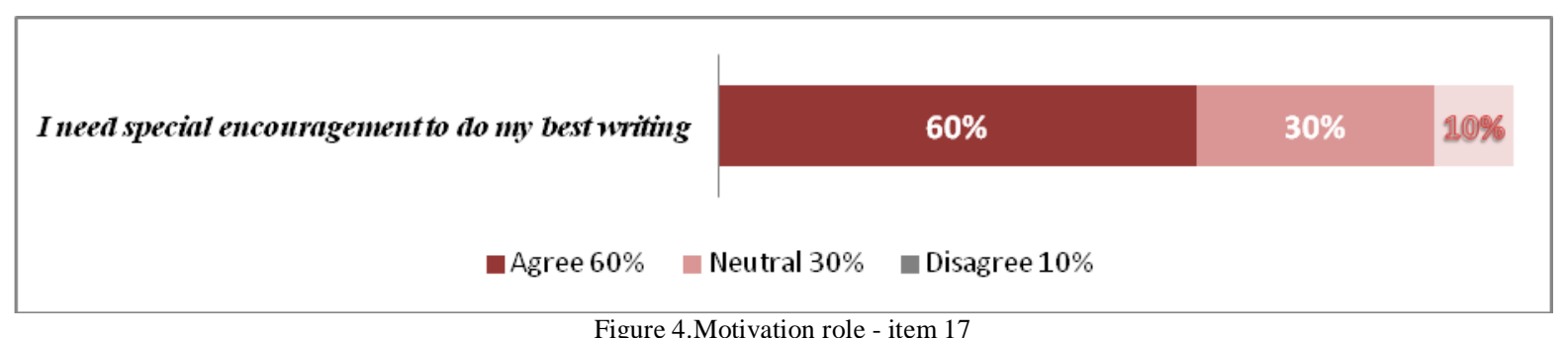

Figure 4.Motivation role - item 17

According to Marshall (1991), the components of writing research are more difficult than using structure and correct grammar usage. This study tackled the issue of research in detail to add to literature more insights. 23 out of 50 students 
(46\%) let their writing happens with little planning while $28 \%$ do not. However, data gathered from participants showed no significant problems in choosing academic research topics or forming research questions to guide the writing process (see figure 5).

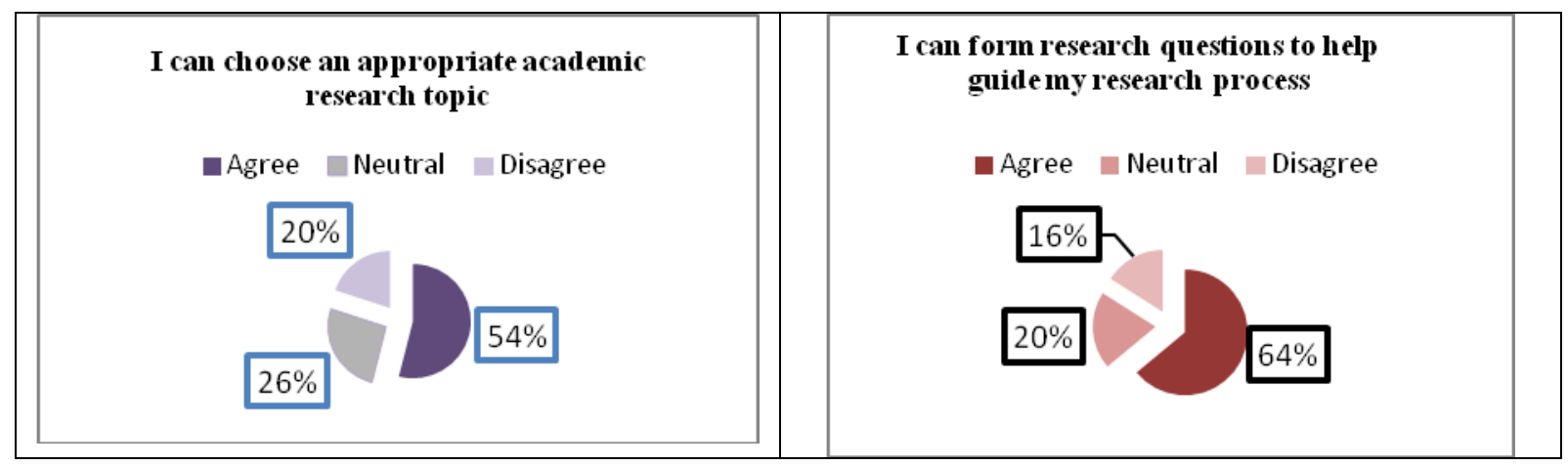

Figure 5. Research topic and questions - items $19 \& 20$

From another angle, data showed that students are hesitant regarding the stage of preparing an outline for their research. 34\% (17 students) selected to be neutral regarding item 21 while 20\% (10 students) admitted having difficulty with working on the outline.

With regard to incorporating other works into their research, almost half of participants (48\%) affirmed having no problem with the technique of paraphrasing whereas 32\% remained neutral. Moreover, $46 \%$ assumed forming accurate quotations in their writings. However, 30\% said that the infamous weakness they suffer from is referencing and citation. Additionally, the majority of participants $(72 \%)$ still believed that writing a research is a slow process that needs time to get it done (See figure 6).

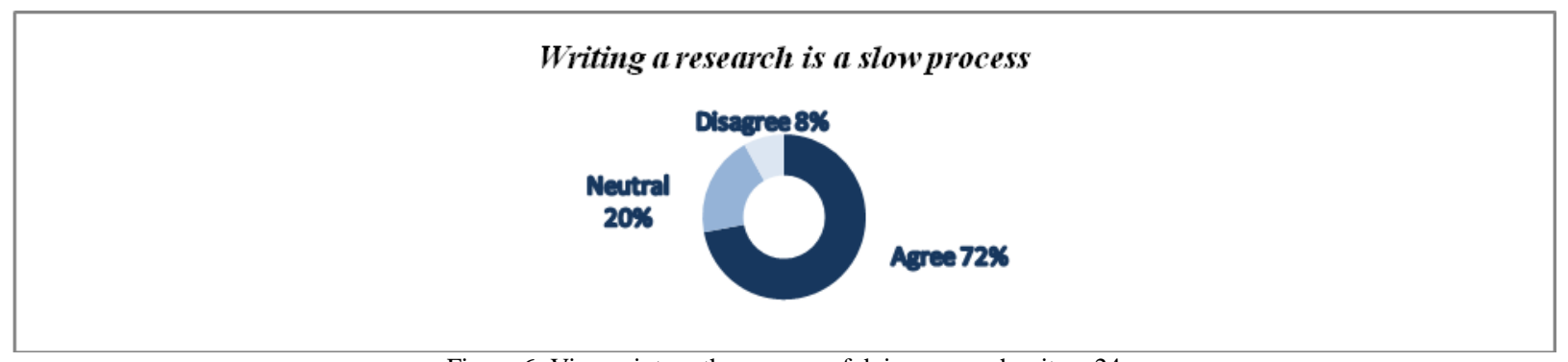

Figure 6. Viewpoint on the process of doing research - item 24

$66 \%$ of participants admitted that they write only to get marks (item 25 ) and that only $18 \%$ believed in their abilities to write a good academic research paper (item 26). Furthermore, 54\% described writing assignments in English to be 'difficult' (item 27).

It can be deduced that there are many reasons that can cause writing difficulty for AIU students taking the AWR course. One reason is because of students' low perception of their English capabilities since they may not have the necessary English language skills to cope with writing assignments, especially when it comes to grammar. Another reason is the lack of motivation as they proved to need encouragement to finish their writing tasks. Additionally, results show that students do barely enjoy writing and that they view it negatively.

With regard to doing research, AIU students seem not to believe in their writing skills to do research which can cause them difficulties in writing. Furthermore, data analysis demonstrates lack of planning for research and that getting stuck at the stage of outlining can reflect destructively on their writing outcome. One last cause of trouble in academic writing can be attributed to referencing and citing, in addition, to admitting that working on research needs plenty of time.

What are some possible ways to address these problems?

Depending on the analysis of data gathered form students at AIU participating in this study, a number of solutions to the difficulties they face in academic writing is presented.

- Having a placement test before the course starts. The purpose is to do intensive proficiency course for those with poor proficiency before getting AWR course.

- Highlighting the importance of writing to students and raising their awareness of its significance.

- Raising students' awareness about the meaning of AWR and increasing their perception of it as they have to enter this "formal" world.

- Redesigning the course book to meet students' needs.

- Enriching the course with materials that can make students practice many more skills.

- Creating space for intensive writing tasks where students can practice more. 
- Creating space for more writing activities and assign extra classes for those who need them.

- Raising awareness of self-editing.

- Exerting more effort to help students write in accordance with a plan (Outline stage).

As of highlighting the role of teachers in helping students overcome the writing problems, the following ideas were suggested:

- Teachers have to play a role in motivating students to become better writers.

- Teachers should help students believe that they can be successful writers if they practice and exert some effort; they must believe that writing is a skill gained through hard work.

- Teachers should believe in their ability to make a change in their classrooms.

\section{DISCUSSION AND CONCLUSION}

Writing is a demanding skill (Reid, 2002) and the body of research has shown that university students have problems regarding academic writing. That is why the current study has aimed at examining this problem from AIU students' perspective in order to find applicable solutions. Results have shown that students have difficulties in revising their own writing pieces as they can hardly detect their mistakes. Additionally, grammatical features form another problem that cannot be overlooked and students proved to pay more attention to the language rather than the content. Students also stressed the importance of their need for motivation to do good writing. Moreover, the majority believed that writing is a slow process that needs lots of hard work. The study concluded by suggesting some ways to deal with the problem.

\section{REFERENCES}

[1] Abdulkareem, M. (2013). An investigation study of academic writing problems faced by Arab postgraduate Students at Universiti Teknologi Malaysia (UTM). Theory and Practice in Language Studies, 3 (9), 1552-1557.

[2] Al Badi, I. (2015). Academic writing difficulties of ESL learners. In the 2015 WEI International Academic Conference Proceedings. Spain, Barcelona.

[3] Al Fadda, H. (2012). Difficulties in academic writing: from the perspective of King Saud University postgraduate students. English Language Teaching, 5 (3). 123-130. Retrieved June 22, 2017, from www.ccsenet.org/elt.

[4] Alfaki, I. (2015). University students' English writing problems: diagnosis and remedy. International Journal of English Language Teaching, 3 (2), 40-52. Retrieved January 8, 2017, from www.eajournals.org.

[5] Al-Khasawneh, F. (2010). Writing for academic purposes: problems faced by Arab postgraduate students of the college of Business, UUM. ESP World, 9 (2), 1-23. Retrieved February 24, 2017, from www.esp-world.info.

[6] Al Murshidi, G. (2014). UAE university male students' interests impact on reading and writing performance and improvement. English Language Teaching, 7 (9), 57-63.

[7] Asadifard, A., \& Koosha, M. (2013). EFL instructors and student writers' perceptions on academic writing reluctance. Theory and Practice in Language Studies, 3 (9), 1572-1578.

[8] Barkaoui, K. (2007). Teaching writing to second language learners: insights from theory and research. TESL Reporter 40, (1), $35-48$

[9] Elbow, P., \& Belanoff, P. (2000). A Community of Writers. 3rd ed. Boston: McGraw Hill. Retrieved January 8, 2017, from https://www.yvcc.edu/resources/the-writing center/Downloads/Writing\%20Skills\%20Questionnaire.pdf.

[10] Isaacson, S. (1996). Simple ways to assess the writing skills of students with learning disabilities. Volta Review, 98 (1), $183-$ 199.

[11] Jimenez, A., Esmeralda, C., Mira, D., Cecilia, D., \& Stephany, G. (2013). An analysis of the writing skill difficulty of the English composition of sStudents at the foreign language department of the University of EL Salvador. (The degree of Licenciadas En Lenguas Modernas Especialidad En Frances E Ingles). Retrieved January 7, 2017, from ri.ues.edu.sv

[12] Kobayashi, H. \& Rinnert, C. (2008). Task response and text construction across L1 and L2 writing. Journal of Second Language Writing, 17(1), 7-29.

[13] Lee, N. (2005). Understanding students' perceptions of difficulty with academic writing for teacher development: A case study of the University of Tokyo writing program. Researchgate, 14, 1-11. Retrieved March 3, 2017, from www.researchgate.net.

[14] Marshall, S. (1991). A genre-based approach to the teaching of report-writing. English for Specific Purposes, 10 (1), 3-13.

[15] Mojica, L. (2010). An investigation on self-reported writing problems and actual writing deficiencies of EFL learners in the beginners' level. TESOL Journal, 2, 24-38.

[16] Pinete, E. (2014). The academic writing challenges of undergraduate students: A South African case study. International Journal of Higher Education, 3 (1), 12-22. Retrieved March 3, 2017, from www.sciedu.ca.

[17] Rabab'ah, G. (2003). Communication problems faced by Arab learners of English. Journal of Language and Learning, 3 (1), $180-197$

[18] Reid J. (2002). Writing. In Ronald Carter and David Nunan (eds). The Cambridge guide to teaching English to speakers of other languages (pp. 28-33). Cambridge: Cambridge University Press. 


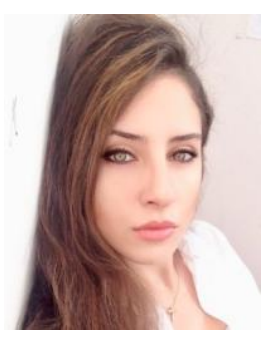

Sarah Al-Mukdad, born in Damascus, Syria, August, 1988. Has a BA in English language and literature at Damascus University (2010) and Got MA in teaching English as a foreign language TEFL at Damascus University (2015).

She has worked for The Higher Language Institute HLI, Damascus, Syria (2013- present). She is teaching English at Damascus University (2011- present) and Arab International University, Damascus, Syria (2014present). 